\title{
Analysis and impact of recent climate trends on grape composition in north-east Italy
}

\author{
Alessia Cogato ${ }^{1,{ }^{*}}$, Franco Meggio ${ }^{2}$, Francesco Pirotti ${ }^{1}$, Alberto Cristante $^{3}$ and Francesco Marinello ${ }^{1}$ \\ ${ }^{1}$ University of Padova, Department of Land, Environmental, Agriculture and Forestry, Italy \\ ${ }^{2}$ University of Padova, Department of Agronomy, Food, Natural Resources, Animals and the Environment, Italy \\ ${ }^{3}$ Vini La Delizia, Casarsa della Delizia, Italy
}

\begin{abstract}
Climate is the most relevant factor influencing the ripening of high quality grapes to produce a given wine style. This notion should be taken into account, given the increase of extreme weather events (EWE) related to climate change. Under this evolving climate scenario, North-East Italian wine regions have seen a recent expansion, potentially disregarding optimal planting choices. The use of marginal land, indeed, could lead to the establishment of vineyards in areas where it is not possible to take advantage of the best row orientation, slope and aspect. Under these conditions, the consequences of some EWE may be more severe. The objective of this study is to verify whether planting options in combination with climate conditions, may affect yield and fruit quality. An area localised in Northern Italy was analysed for row orientation and slope, taking advantage of QGIS tools. The area was also examined for climate conditions, using weather conditions and climate indices. Such variables were combined with 10-year yield and must composition of four varieties (Chardonnay, Pinot Gris, Merlot and Glera) by using linear regression. The paper reports the most significant relationships between climatic conditions and grapevine composition. The results showed high positive correlation between sugar concentration and the number of frost days during the year in three varieties. The sugar content was positively correlated with the relative humidity in June in three varieties and negatively correlated with the number of days with a temperature $>25^{\circ} \mathrm{C}$ during the month of June in two varieties. The content of tartaric acid showed high correlations with thermal indices of May in all varieties
\end{abstract}

\section{Introduction}

In viticulture and wine production, climate is probably the most critical factor influencing fruit ripening, the main requirement to achieve optimal characteristics to produce a given wine style. Climate is one of the elements of the terroir, defined as the natural potentialities of a given place which might influence the characteristics of an agricultural product [1]. Regions that historically have been more involved in viticulture have succeeded in gaining the best possible benefits from climate conditions, optimising terroir expression. In these regions, wine production is a relevant economic sector, and winemakers aim to build their reputation by providing consistent quality.

According to the World Meteorological Organization and the Intergovernmental Panel on Climate Change, the climate is changing, and the world is experiencing unprecedented climate extremes. Climate change, indeed, arises as an increase of extreme and uncertain events [2-5]. Traditional wine-growing regions will face more frequent and intense extreme weather events (EWE) $[2,3]$. This climate change scenario will likely influence the main viticultural choices, i.e. rootstock/scion combination, or even alter the geographical distribution of currently used grapevine varieties [6]. This situation would mean a drastic change, since existing varieties are the result of the selection based on the climatic conditions of the areas where they are grown [7]. Such change could lead to the selection or introduction of new grapevine varieties to cope with abiotic stresses associated with EWE [8]. Many authors have focused on the effects of climate change on grapevine physiology. The effects of increased UV-B on berry composition have been extensively studied, leading to reduced chlorophyll and carotenoid concentrations [9]. Drought has been found to cause stomata closure and reduced photosynthesis with a subsequent decrease in yield. Moreover, the combination of drought and heat waves may cause incomplete berry maturation [10]. On the other hand, studies have shown how water deficit can promote the synthesis of important metabolites. In Cabernet Sauvignon, water stress accelerated the accumulation of anthocyanins and had a positive effect on the expression of key genes involved in anthocyanin biosynthetic pathways [11]. In Chardonnay, water deficit led to an increase of flavonol concentration [12]. Under this climatic scenario, the 
maintenance of consistently high quality in viticulture is becoming challenging.

Climate change's impact on viticulture creates the need of innovative vineyard establishment techniques and cultural practices allowing a minimization of the adverse effects related to EWE or, conversely, the ability to take advantage of them [13-17]. Within vineyard establishment solutions, row orientation is essential, as it affects plant radiation interception and therefore the wine quality $[18,19]$. Row orientation has been demonstrated to affect canopy microclimate, in terms of leaf temperature, relative humidity and photosynthesis [20]. Similar studies showed that row orientation affects many crop parameters, such as shoot length, leaf area, bud fruitfulness and berry mass and, as a consequence, fruit ripening and harvest period [15]. Innovative cultural practices have been recently developed to cope with current climate change. Delayed cane winter pruning [17] or the use of antitranspirants [16] allowed the manipulation of the ripening process to deal with multiple summer stresses.

Despite the high number of studies concerning the effects of climate change on grapevine quality, an analysis of the consequences of the yearly fluctuations of meteorological conditions on berry quality is still lacking. One of the primary needs of viticulture is to exploit the possibility of using short and medium-range weather forecasts for managing vineyards as based on decision support system (DSS) warnings. DSS uses historical data as a starting point to build forecasting models.

The primary objective of this study was to verify the effects of yearly and monthly EWE on grapevine quality. Moreover, the study investigated whether some viticultural technical and management decisions might affect vine yield and fruit composition.

An area localised in Northern Italy was analysed, taking advantage of GIS tools. Yearly weather conditions were correlated with 10 -year yield and must chemical composition.

The goal of this work is to create forecasting models allowing a connection between climatic conditions and grapevine yield and quality responses. This information could help orient future planting choices by taking into account restrictions imposed by increased EWE.

\section{Material and methods}

The study was conducted in an area belonging to a winegrowers' cooperative located in Friuli Venezia Giulia region, in the North-East of Italy (Fig. 1). The company rates more than 500 associated wine growers with 2000 hectares of vineyards that extend throughout the Friuli plain. The main grapevine varieties grown by the company are two white wine varieties (Glera and Chardonnay), one grey (Pinot Gris), and one red (Merlot).

The study took advantage of a reference dataset which included 42708 analyses of grapes measured at harvest by FITR with Oenofoss (FOSS. Electric, Denmark) for a period of 10 years from 2008 to 2017 in the study area. For each year, at harvest, 12 parameters were measured for each grape analysis, which can be grouped into four main categories: parameters concerning ripening, acidity scores, crop health and chemical characteristics.

With regard to the meteorological data, a total of 28 indices were considered among: bioclimatic (6) and climate extremes (22) indices (chosen from the ones defined by the European Climate Assessment and Dataset).

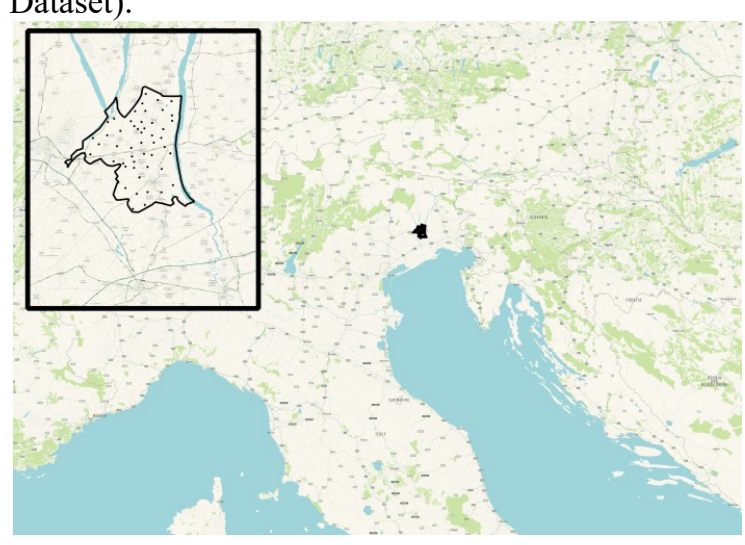

Fig. 1. Case study area and sample vineyards.

The climate extremes indices were calculated both yearly and monthly, based on six weather stations placed within the study area. Since the data collected by the weather stations showed a non-significant difference, revealing a very homogeneous area, a new dataset was developed, including the mean of daily rainfall, temperature and relative humidity among the six stations. The first analysis performed was the extraction of geo-data, carried out through QGIS software. Fifty vineyards were randomly selected within the study area and analysed to detect planting distance, pruning system, slope grade and row orientation. The same parameters were estimated in 200 vineyards randomly chosen within the region for comparison. The first analysis aimed at verifying if the topographical and management characteristics might influence the meteorological parameters.

The following analysis dealt with quantification of the correlations between climate and harvest data, utilising regression analysis. The linear regression analysis was then focused on those correlations performing high Pearson coefficients $(r \geq \pm 0.85)$.

\section{Results}

The GIS analyses related to topography features of the sample vineyards highlighted a remarkably uniform slope grade within the study area. The mean slope grade of the sample vineyards was $1.03^{\circ}$ with a standard deviation of $0.2^{\circ}$ (Fig. 2). The plants were mostly trained to a VSP (vertical shoot positioning) trellis system, with an average planting distance between rows of $2.7 \mathrm{~m}$. The prevailing row orientation was North-South, as featured by $68 \%$ of sample plots. The comparative analysis on the 
200 vineyards located within the region led to similar results: the mean slope was $1.14^{\circ}$ with a standard deviation of $0.8^{\circ}$, with a prevailing North-South row orientation $(76 \%)$. The results of such topographical situations, combined with the nature of soil and weather conditions, can be different. On one hand, the flatland encourages water infiltration, on the other hand it might lead to waterlogging risk. As far as for row orientation, the prevailing North-South orientation is the ideal choice at northern latitudes because it leads to a better radiation balance for the canopy, especially in vertical trellis systems. In such a situation, the microclimate is improved by a subsequently lower humidity within the canopy.

The results of the geo-data analysis showed that the study area was very uniform. In contrast, figures 3 and 4 show the considerable variability of climate and harvest data.

Referring to GIS and climate analysis, most of the differences within grape and must parameters were ascribable to the latter.

The regression analysis highlighted several correlations between climate and harvest data. Particular attention was paid to the correlations with higher $\mathrm{R}^{2}$ coefficients.

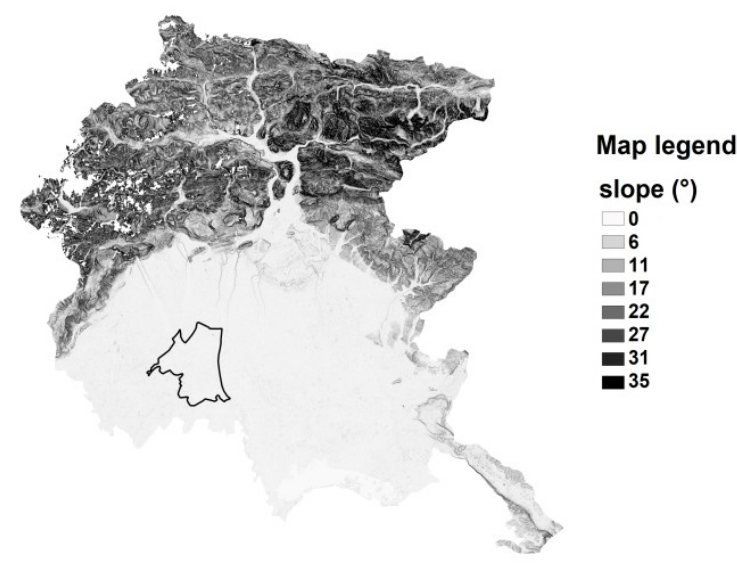

Fig. 2. Mean slope grade in the study area and in the whole Region.

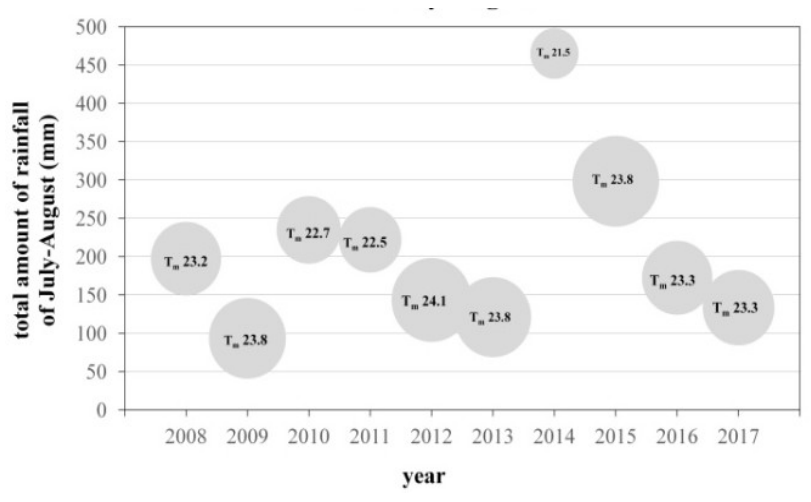

Fig. 3. Cumulative rainfall from July to August; data pooled over 10 years (2008-2017). The diameter of the circles represents the mean temperature in the two months.

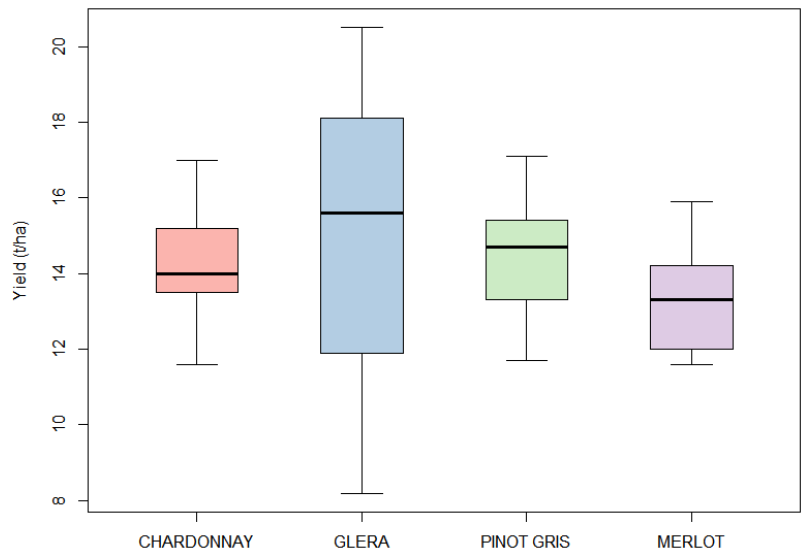

Fig. 4. The box plot describes the distribution of yield (tons per hectare) of the four varieties over the period considered (20082017).

\subsection{Must sugar concentration}

The statistical analysis highlighted correlations between must sugar concentration and thermal indices. A positive correlation was observed between the sugar concentration at harvest and FD (frost days per year) for most of the varieties. Specifically, Chardonnay showed a positive correlation with $\mathrm{R}^{2}=0.787$, Merlot with $\mathrm{R}^{2}=$ 0.769 and Glera with $\mathrm{R}^{2}=0.738$ (data not shown). An inverse correlation resulted, instead, with SU (number of "summer days", days with mean daily maximum temperature higher than $25^{\circ} \mathrm{C}$ ) in June in Chardonnay $\left(R^{2}=0.773\right)$ and Merlot $\left(R^{2}=0.874\right)($ Fig. 5).

Three varieties (Merlot, Chardonnay and Pinot Gris) exhibited a direct correlation with the relative humidity of June (R2 $=0.882, \mathrm{R} 2=0.878$ and R2 $=0.847$, respectively) (Fig. 6). The high relative humidity did not represent a threat for fungal diseases, as this high humidity event occurred while the three varieties were at their bloom-stage. Vice versa, higher values of relative humidity at this stage may have affected the bloom process resulting in lighter and sparser clusters with smaller berry dimensions, allowing an increase of sugar accumulation as well as phenolic compounds such as carotenoids.

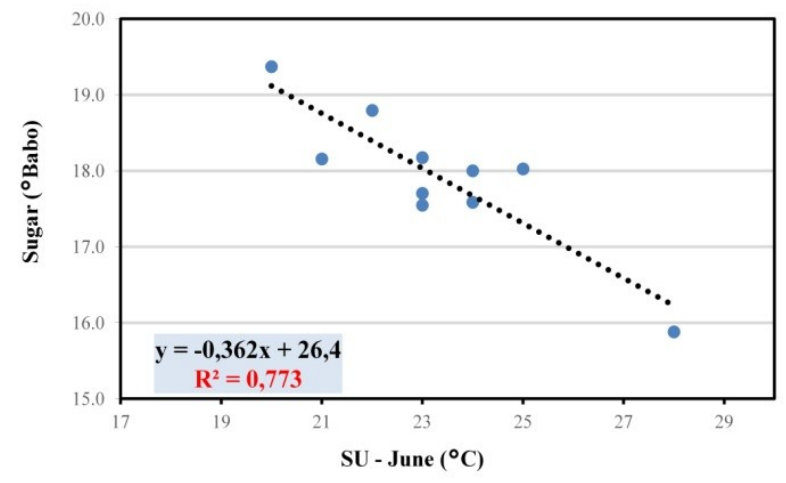

Fig. 5. Inverse correlation between must sugar concentration in Chardonnay grapes at harvest and SU in June (number of summer days, days with mean daily maximum temperature $>$ $25^{\circ} \mathrm{C}$ ). 


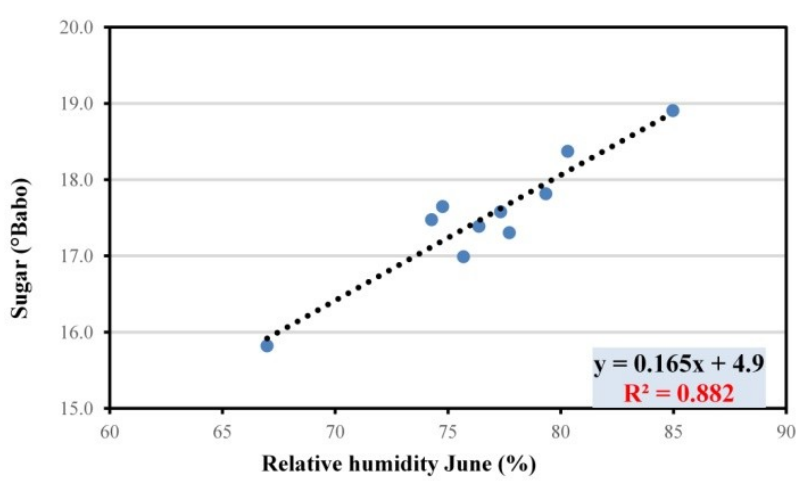

Fig. 6. Direct correlation between must sugar concentration at harvest in Merlot grapes and air relative humidity in June.

\subsection{Tartaric acid}

All the varieties showed a direct correlation between the must tartaric acid concentration at harvest and TG (mean of daily mean temperatures) and TX (mean of daily maximum temperatures) in May (Fig. 7 and 8). In Pinot Gris and Merlot, a positive correlation was also found between tartaric acid concentration at harvest and TN (mean of daily minimum temperatures) in May. Table 1 reports the statistics of the correlations with the thermal indices of May. Correlations between must tartaric acid concentration at harvest and thermal indices in May gave evidence of the importance of this month. A warmer spring, indeed, might have promoted unbalanced vines with higher vegetative growth that, in particular when followed by rainy and warm summers, may have increased vine vigour, affecting canopy microclimate and thus radiation interception by the bunches, resulting in a lower acid decrease during grape ripening, resulting in the higher tartaric acid content measured at harvest.

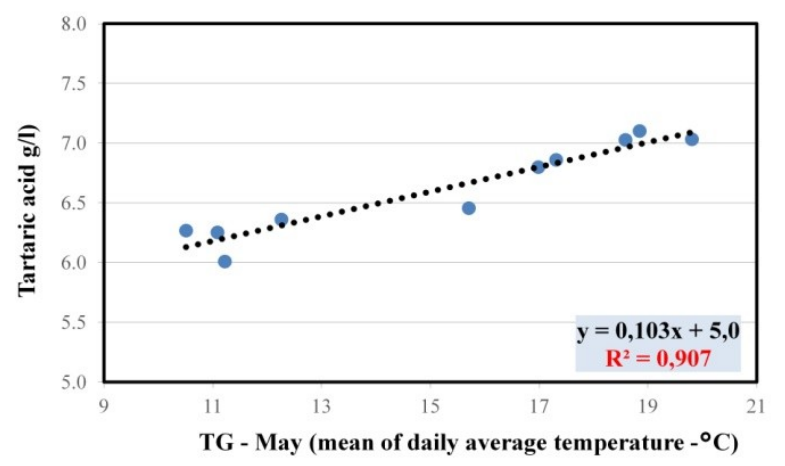

Fig. 7. Direct correlation between tartaric acid concentration at harvest in Pinot Gris juice and daily average temperature in May.

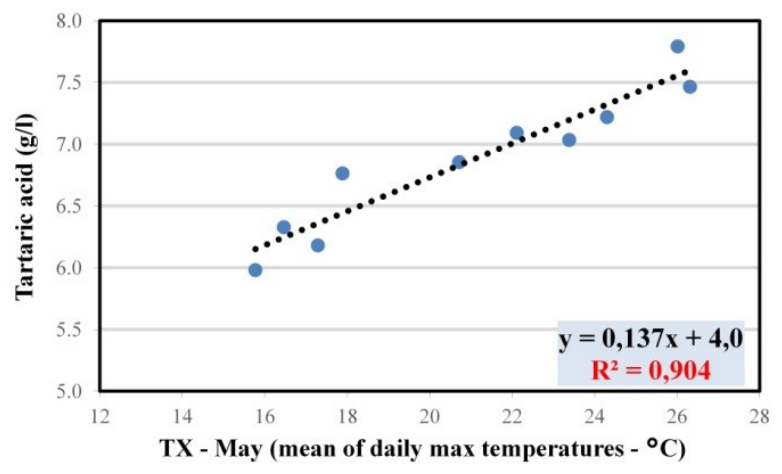

Fig. 8. Correlation between tartaric acid concentration at harvest in Merlot juice and mean maximum temperature in May.

Tab.1. Statistics of the correlations of tartaric acid content at harvest with the thermal indices of May $(\mathrm{C}=$ Chardonnay, $\mathrm{PG}=$ Pinot Gris, $\mathrm{M}=$ Merlot, $\mathrm{G}=$ Glera)

\begin{tabular}{|c|c|}
\hline Thermal index & $\begin{array}{c}\text { Linear } \\
\text { regression }\end{array}$ \\
\hline \multirow{2}{*}{$\begin{array}{l}\mathrm{TN} \text { (mean of daily minimum } \\
\text { temperatures) }\end{array}$} & $\begin{array}{l}\mathrm{y}=0.107 \mathrm{x}+5.6 \\
\mathrm{R}^{2}=0.794 ; \mathrm{PG}\end{array}$ \\
\hline & $\begin{array}{c}\mathrm{y}=0.152 \mathrm{x}+5.4 \\
\mathrm{R}^{2}=0.752 ; M\end{array}$ \\
\hline \multirow{4}{*}{ TG (mean of daily mean temperatures) } & $\begin{array}{c}\mathrm{y}=0.072 \mathrm{x}+5.4 \\
\mathrm{R}^{2}=0.738 ; C\end{array}$ \\
\hline & $\begin{array}{l}\mathrm{y}=0.103 x+5.0 \\
\mathrm{R}^{2}=0.907 ; P G\end{array}$ \\
\hline & $\begin{array}{c}\mathrm{y}=0.149 \mathrm{x}+4.6 \\
\mathrm{R}^{2}=0.876 ; M\end{array}$ \\
\hline & $\begin{array}{c}\mathrm{y}=0.123 \mathrm{x}+3.5 \\
\mathrm{R}^{2}=0.811 ; G\end{array}$ \\
\hline \multirow{4}{*}{$\begin{array}{l}\text { TX (mean of daily maximum } \\
\text { temperatures) }\end{array}$} & $\begin{array}{c}\mathrm{y}=0.065 \mathrm{x}+5.1 \\
\mathrm{R}^{2}=0.746 ; C\end{array}$ \\
\hline & $\begin{array}{l}\mathrm{y}=0.094 \mathrm{x}+4.7 \\
\mathrm{R}^{2}=0.903, P G\end{array}$ \\
\hline & $\begin{array}{c}\mathrm{y}=0.137 \mathrm{x}+4.0 \\
\mathrm{R}^{2}=0.904, \mathrm{M}\end{array}$ \\
\hline & $\begin{array}{c}\mathrm{y}=0.115 \mathrm{x}+3.0 \\
\mathrm{R}^{2}=0.813, \mathrm{G}\end{array}$ \\
\hline
\end{tabular}

\section{Conclusions}

After verifying a high uniformity of the topographical characteristics, this study focused on the effects of the weather parameters on the harvest data. Some general considerations concerning the interactions between climate conditions and must quality have been highlighted by the results of the data. The correlations showed in the results section highlighted the importance of temperature and relative humidity conditions during the first phenological stages. Some of the resulting correlations are just validating well-known concepts. Others need further consideration because of the potential benefit they could lead to viticultural management choices, regarding vineyard establishment, canopy management and irrigation. 
The present project is funded by Italian Ministry of Research and University (MIUR) in the frame of SIR 2014, cod. RBSI14H5R0.

\section{References}

1. G. T. Van Leeuwen, C. Seguin, J. Wine Res., 17 (1), 1-10 (2006)

2. C. Frei, R. Schöll, S. Fukutome, J. Schmidli, P. L. Vidale, J. Geophys. Res. Atmos., 111 (6), 122 (2006)

3. C. Schär, P. L. Vidale, D. Lüthi, C. Frei, C. Häberli, M. A. Liniger, C. Appenzeller, Nature, 427 (6972), 332-336 (2004)

4. M. D. Smith, J. Ecol., 99 (3), 651-655 (2011)

5. E. M. Fischer, U. Beyerle, R. Knutti, Nat. Clim. Chang., 3 (12), 1033-1038 (2013)

6. P. Kenny, G. J. Harrison, J. Wine Res., 3 (3), 163-183 (2007)

7. G. V. Jones, M. A. White, O. R. Cooper, K. Storchmann, Clim. Change, 73 (3), 319-343 (2005)

8. H. Fraga, A. C. Malheiro, J. Moutinho-Pereira, J. A. Santos, Int. J. Biometeorol., 57 (6), 909925 (2013)

9. H. R. Schultz, Aust. J. Grape Wine Res., 6 (1), 2-12 (2000)

10. M. M. Chaves, O. Zarrouk, R. Francisco, J. M. Costa, T. Santos, A. P. Regalado, M. L. Rodrigues, C. M. Lopes, Ann. Bot., 105 (5), 661-76 (2010)

11. S. D. Castellarin, M. A. Matthews, G. Di Gaspero, G. A. Gambetta, Planta, 227 (1), 101112 (2007)

12. L. G. Deluc, D. R. Quilici, A. Decendit, J. Grimplet, M. D. Wheatley, K. A. Schlauch, JM. Mérillon. J. C. Cushman, G. R. Cramer, BMC Gen, 10, art. 212, 1-33 (2009)

13. S. Palliotti, A. Tombesi, S. Silvestroni, O. Lanari, V. Gatti, M. Poni, Sci. Hortic., 178, 4354 (2014)

14. C. Van Leeuwen, P. Darriet, J. Wine Econ., 11 (1), 150-167 (2016)

15. J. J. Hunter, C. G. Volschenk, R. Zorer, Eur. J. Agron., 84, 47-57 (2017)

16. S. Gatti, M. Galbignani, M. Garavani, A. Bernizzoni, F. Tombesi, S. Palliotti, A. Poni, Aust. J. Grape Wine Res., 22 (2), 245-255 (2016)

17. S. Gatti, M. Pirez, F. J. Frioni, T. Squeri, C. Poni, Aust. J. Grape Wine Res., 24 (3), 305316 (2018)

18. I. Campos, C. M. U. Neale, A. Calera, Aust. J. Grape Wine Res., 23 (1), 77-86 (2017)

19. D. Grifoni, G. Carreras, G. Zipoli, F. Sabatini, A. Dalla Marta, S. Orlandini, Int. J.
Biometeorol., 52 (8), 755-763 (2008)

20. J. J. Hunter, C. G. Volschenk, R. Zorer, Agric. For. Meteorol., 228-229, 104-119 (2016) 